\title{
EXAMINING THE COMPELLINGNESS OF ELECTRONIC LOW VISIBILITY TAXI CHARTS
}

\author{
Michelle Yeh, ${ }^{1}$ Joseph Jaworski, ${ }^{2}$ Suzanne Thomas, ${ }^{2}$ Andrew Kendra, ${ }^{3}$ Danielle Hiltunen ${ }^{4}$ \\ ${ }^{1}$ Federal Aviation Administration \\ ${ }^{2}$ Cherokee CRC, LLC \\ ${ }^{3}$ United States Department of Transportation, Volpe National Transportation Systems Center \\ ${ }^{4}$ Stinger Ghaffarian Technologies, Inc.
}

\begin{abstract}
The purpose of this study was to examine whether the presentation of own-aircraft (ownship) position was compelling when presented on electronic low visibility taxi charts. Although airport charts showing ownship position have been in use for some time, ownship position was not available on low visibility taxi charts because these charts were not geo-referenced. Twenty Airline Transport Pilots (ATP) (10 flightcrews) participated in a simulator study in which they performed six taxi scenarios in three different levels of visibility (1200 Runway Visual Range (RVR), 600 RVR, 300 RVR) using an electronic chart application on an iPad. Ownship position was shown on the chart for half the scenarios. In one scenario, we simulated a position error. We collected objective data (taxi speed, taxi time, fixation and dwell time), and pilot opinions on the usability of the electronic chart application. The results showed that no incursions/excursions were committed. All flightcrews noticed the error in ownship position, when it occurred; in fact, they also noticed other errors in ownship position that were not planned as part of the experiment design. Captains looked more often at the electronic chart when ownship position was presented than when it was not, regardless of visibility conditions. Additionally, Captains' percentage of fixations were almost equal between the electronic chart and out-the-window. Such behavior may reflect the perceived utility of showing ownship on the electronic chart and may be an indication of the compelling nature of that information source.
\end{abstract}

\section{INTRODUCTION}

Pilots are presented with a variety of information sources that must be integrated, from the out-the-window view to installed avionics to portable electronic devices (PEDs). The attention allocated to each of these information sources may be driven by several factors, including the effort to access information, the effort to extract the information, and the perceived usefulness of the source. The value associated with each of these factors will vary depending on the task being performed (Wickens, Goh, Helleburg, Horrey, \& Talleur, 2003). Underlying all these factors is the compellingness of the information presentation.

The term "compelling” is defined in this paper as a display property that attracts interest or attention potentially at the cost of attention to other information sources, such as other displays or out-the-window. Compellingness can be observed as attentional tunneling. Several factors contribute to making a display appear compelling, such as salience, realism, and resolution, to name a few (Wickens \& Alexander, 2009). A display that is compelling can have both positive and negative effects on human performance. Compellingness can be beneficial, when attention is drawn to information when that information is time-critical (e.g., alerts) or when information is presented in such a way that it reduces the "cost" of accessing or integrating that information. However, compellingness can be problematic if the information display is distracting (for example, a display that attracts attention at the cost to other information sources) or if that information is used inappropriately. For example, the presentation of information superimposed on a head-up display may be more compelling than information presented in a head-down location to the extent that the imagery "captures" the pilots' attention at the cost of information beyond the symbology (the out-thewindow view; Yeh \& Wickens, 2001).

The issue of compellingness has also been explored relative to use of electronic flight bag (EFB) applications and PEDs. Much of the evidence for the compellingness of these displays comes from the general aviation domain (Part 23 operations) where use of PEDs has led to increased head-down time. Reports from the Aviation Safety Reporting System (ASRS) provide examples where general aviation pilots committed errors (e.g., airspace violation) because they paid more attention to incorrect or out-of-date global positioning system (GPS) information on their portable device (e.g., smart phone, tablet, laptop) rather than their installed avionics displays. That is, information that was provided for strategic purposes was used tactically. Additionally, pilots noted they were learning to use the device during the flight or that they became lost in the wealth of information available on the PED (Joslin, 2013).

Given the perspective provided in the general aviation domain, we were interested in understanding how flightcrews use EFB applications in air transport operations (Part 121) for position awareness only. The purpose of this study was to examine whether the presentation of own-aircraft (ownship) position contributes to compellingness in the context of low visibility taxi scenarios. Airport markings (e.g., geographic position markers (GPMs), runway guard lights, and stop bars) as well as special low visibility taxi charts help flightcrews maneuver in low visibility conditions. The presentation of ownship position on a low visibility taxi chart could facilitate position awareness but bring the pilot's eyes away from the out-the-window view for a longer than optimal period. Even in 
low visibility conditions, it is the out-the-window view that contains important information to determine aircraft position and avoid obstacles.

Flightcrews conducted 6 taxi scenarios (3 taxi in, 3 taxi out) in 3 levels of visibility (1200 Runway Visual Range (RVR), 600 RVR, and 300 RVR) in nighttime lighting conditions using specially-designed prototype geo-referenced electronic low visibility taxi charts. For half the scenarios, ownship position was presented on the electronic chart. Low visibility taxi charts are different from traditional airport diagrams in that they identify specific routes and cues to help pilots maintain position awareness when the visibility of traditional out-the-window cues (e.g., taxi signs, edge line lights) is limited. Although airport charts showing ownship are in widespread operational use, electronic low visibility taxi charts did not show ownship position at the time we conducted this study because the charts were not geo-referenced and thus could not meet the accuracy required by the Federal Aviation Administration (see Advisory Circular (AC) 120-76D, Authorization for Use of Electronic Flight Bags).

This study was originally intended to replicate an experiment conducted by a charting provider, in which the sample size and data analysis were limited due to time constraints. This replication was an attempt to combine the data samples from the two studies to allow for significance testing. However, we made some modifications to the experiment design to correct some issues identified during the conduct of the previous study. For example, we re-designed some taxi routes so that the direction in which own-aircraft was taxiing was consistent with that shown on the low visibility taxi charts, and we shortened the length of some scenarios so that the study could be conducted within the time allotted. These modifications prevented any combination of the data.

\section{METHOD}

\section{Participants}

Twenty Airline Transport Pilots (ATP) participated in the study. The mean age for the participants was 45 , with a range from 31 to 53 years old. Pilots were paired to form 10 two-person flightcrews. Each participant flew the same position in the study as their position in flight operations, with one exception in which one Captain participated as a First Officer.

\section{Simulators}

The study was conducted using two Boeing 737 commercial aircraft simulators, without motion. Two crews were run simultaneously. Electronic taxi charts were presented on two iPads with 9.7" screens located in the areas of the left and right side flight deck window with the GPS signal simulated through a portable Bluetooth device. The iPads were fixed in place.

Eye tracking glasses were available for only one of the simulators. The glasses recorded pilot's gaze behavior in realtime for six crews. For the simulator without eye tracking glasses, a video camera was placed in the simulator to capture pilot head movement and voice data. These data were analyzed separately from the eye tracking data.

\section{Experiment Design}

The study was a 2 (Ownship: on, off) x 3 (RVR: 1200, $600,300)$ x 2 (Group: 1, 2) mixed design. Ownship and $R V R$ were manipulated within subjects, so each flightcrew saw all three visibility levels and two levels of ownship presentation (on/off).

Group (1 or 2 ) was a between-subjects variable that described the manipulation of ownship presentation within the scenarios. Six scenarios were developed for this study, consisting of one taxi-in and one taxi-out scenario for each RVR level. The scenarios were specific to the RVR level because only certain taxi routes are available as visibility decreases. Each flightcrew had ownship on for either the taxi in or the taxi out scenario, but not both. The Group variable is further described in Table 1 below.

Table 1. Experiment Design

\begin{tabular}{|l|c|c|c|}
\hline \multicolumn{1}{|c|}{ Group 1 } & 1200 RVR & 600 RVR & 300 RVR \\
\hline Ownship on & IN & OUT & IN \\
Ownship off & OUT & IN & OUT \\
\hline
\end{tabular}

\begin{tabular}{|l|c|c|c|}
\hline \multicolumn{1}{|c|}{ Group 2 } & 1200 RVR & 600 RVR & 300 RVR \\
\hline Ownship on & OUT & IN & OUT \\
Ownship off & IN & OUT & IN \\
\hline
\end{tabular}

\section{Scenarios}

Each flightcrew completed a taxi-in and taxi-out at Denver International Airport (DEN) for each RVR condition; a total of six scenarios. All taxi-out scenarios began on the apron. All taxi-in scenarios started on the Instrument Landing System (ILS) final approach three miles out from the touchdown position of the runway in use, with the aircraft fully configured for landing (i.e., gear-down, flaps-full, final checklist checked, and aircraft stabilized for landing). When ownship position was shown, the ownship icon was displayed only when the aircraft speed was below 80 knots. Ownship position was not shown on approach charts during flight. All trials were conducted in a simulated night environment. No traffic aircraft were introduced in the scenarios. However, the scenarios were still operationally realistic because air traffic control would limit the number of aircraft on active taxiways and runways and increase the distance aircraft maintain from one another in low visibility conditions. Consequently, traffic aircraft would not be visible to ownaircraft.

The duration of each trial was approximately 10-15 minutes. Each set of six scenarios was completed during an approximate two-hour simulator time block. The order in which the visibility conditions (and hence the scenarios) were presented was counterbalanced for each group. 
To gather data on whether ownship position was compelling, we presented flightcrews with one off-nominal scenario in which we simulated a GPS failure and ownship position froze on the electronic airport chart. This presentation was a deviation from FAA policy, which requires ownship position to be removed when the GPS signal is lost. This GPS failure was presented to flightcrews only once, and on the final trial in which ownship position was depicted.

\section{Procedure}

The study took approximately two-and-a-half hours to complete. Flightcrews began with a 15-minute pre-briefing, followed by approximately two hours in the simulator, and a 15-minute de-brief to pilots. During the pre-brief, flightcrews completed the informed consent form, received an overview of what to expect in the simulator, and completed a background questionnaire. Once in the simulator, a researcher calibrated the eye tracking glasses for each pilot if the simulator was equipped with the eye tracking system.

Flightcrews first completed a practice scenario in 1200 RVR daytime conditions to familiarize themselves with the airport layout and simulator. Following the practice trial, flightcrews completed the six taxi scenarios in a nighttime environment. Pilots selected the charts for use during each scenario, and were allowed to switch between low visibility taxi charts, and airport diagrams as needed. The experimenter pre-loaded the chart for the first trial and the pilots loaded all subsequent charts. Assigned breaks were not included; however, crews were instructed to inform the experimenter should they want a break.

One researcher acted as an air traffic controller for each simulator, providing all taxi instructions and responding to any calls the crews made to Air Traffic Control (ATC). The researcher was seated inside the simulator with the crew. In the off-nominal scenario, this researcher also initiated the GPS failure using a smartphone application to toggle the Bluetooth connection to the simulator off. This simulated a GPS "freeze." Once the flightcrew noticed the disparity in the ownship presentation, the researcher turned the Bluetooth connection back on, which simulated the GPS signal being reacquired.

After each scenario, each flightcrew member completed an electronic post-scenario questionnaire to gather subjective data about the use of the electronic chart and general usability issues. Following the sixth trial, each flightcrew member also completed a post-test questionnaire to gather overall impressions regarding the presentation of ownship.

\section{RESULTS}

Our data set consisted of objective data collected from the simulator (taxi speed and taxi time) and eye trackers (number of fixations, dwell time on areas of interest) and subjective data from the post-scenario and post-test questionnaires. Data for nine flightcrews were included in the data analysis; one flightcrew was excluded because the Captain was not current.

\section{Taxi Speed and Taxi Time}

We analyzed the data for taxi speed and taxi time using a 2 (ownship) x 3 (RVR) ANCOVA. Simulator data were collected at a sampling rate of $10 \mathrm{~Hz}$. Direct comparisons by RVR were not possible because the taxi route differed depending on the RVR level. Consequently, we introduced two variables (taxi route length and complexity) as covariates to "normalize" the differences in the taxi route. Although nine flightcrews were included in the analysis for each trial, we excluded flightcrews for trials in which a simulated GPS error occurred, or problems with the simulator data collection or failures to follow experimental protocol were observed. The number of flightcrews used for the analysis is shown in Table 2 below.

Table 2. Number of Flightcrews for Taxi Speed and Taxi Time Analysis

\begin{tabular}{|l|c|c|}
\hline RVR & Ownship On & Ownship Off \\
\hline 300 & $n=4$ & $n=7$ \\
\hline 600 & $n=5$ & $n=5$ \\
\hline 1200 & $n=5$ & $n=6$ \\
\hline
\end{tabular}

Neither ownship position nor RVR significantly affected taxi time or taxi speed.

We also examined the number of errors committed by counting the number of incorrect or missed turns. Each scenario contained between 4-8 turns. There were a total of 101 potential opportunities for error in the scenarios when ownship was available and 159 when ownship was not. Only three taxi errors were committed overall - all occurring when ownship was not shown (1.9\%). Two of the errors occurred in 1200 RVR conditions, possibly because the taxi route for that scenario spanned two charts and required more flightcrew interaction than the other scenarios. The third error occurred in 300 RVR conditions. All three errors were identified by the flightcrews and reported to ATC.

\section{Eye Tracking}

Eye movement was collected at $60 \mathrm{~Hz}$. Eye tracking data were collected for only six flightcrews (totaling 72 videos). From this data set, we excluded 12 videos related to the GPS error, four videos due to violations of the experimental protocol, and one video due to equipment malfunctions. In total, we examined 55 eye tracking videos to examine where pilots looked, how often (number of fixations) and for how long (dwell time). We defined four areas of interest: out-thewindow (OTW), instruments/controls, own EFB, and other (fixations that did not fall within one of the previous three areas of interest). Figure 1 shows the areas of interest defined for the Captain (left seat). 


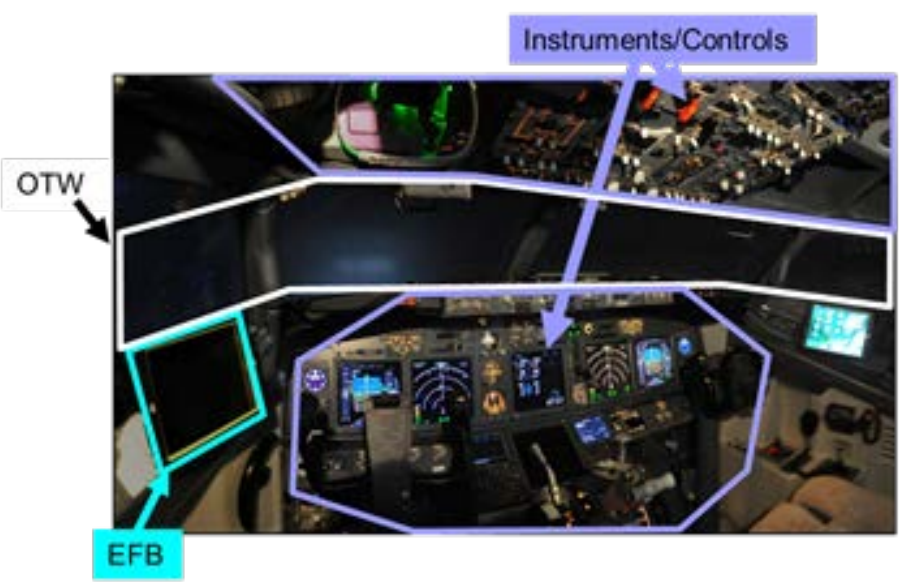

Figure 1. Areas of interest as defined for the Captain.

The eye tracking data were analyzed separately for Captains and First Officers because of the different tasks they performed. In our study, Captains maneuvered the aircraft whereas First Officers were responsible for visually monitoring the progress of the aircraft and ATC communications. Thus, we expected what they looked at and for how long to differ. The percentage of fixations and overall dwell time were analyzed using multiple one-way ANCOVAs. In first examining the data for the Captains, the results showed that Captains had significantly more fixations on the EFB when ownship was presented than when it was not, $F(1,25)=$ $9.61, p=.005$. Captains also spent more time looking at the EFB overall when ownship was presented than when it was not, $F(1,25)=6.42, p=.019$. We found no difference in the mean dwell time for each fixation to the electronic chart as a function of ownship position $(\mathrm{F}(1,25)=0.87, \mathrm{p}=0.36)$. Figure 2 shows the percent fixations in each area of interest. Figure 3 shows the percent dwell time as a function of ownship (on vs. off). As Figure 2 shows, Captains looked at their EFB almost six times more when ownship was on than when it was off. Figure 3 shows that the amount of time Captains looked at the EFB also increased by almost six times when ownship was present than when it was not, and that this time spent looking at the EFB was "borrowed" from time spent looking out-the-window. Finally, the figures show that the number of times (i.e., percent of fixations) and the amount of time Captains spent looking at their instruments did not change significantly as a function of ownship presence (or absence).

This data suggests that the presentation of ownship position was compelling but does not speak to why. We hypothesize that ownship position increased the perceived usefulness of the electronic chart/EFB to the Captain. This is supported by subjective data from flightcrews who indicated that electronic charts with ownship position increased the time available for crew duties. Because Captains were responsible for taxiing the aircraft (i.e., eyes-out), the "cost" of information access-looking at the electronic chart and correlating the chart to the out-the-window view to verify position - was significantly lower when ownship was present than when it was not.

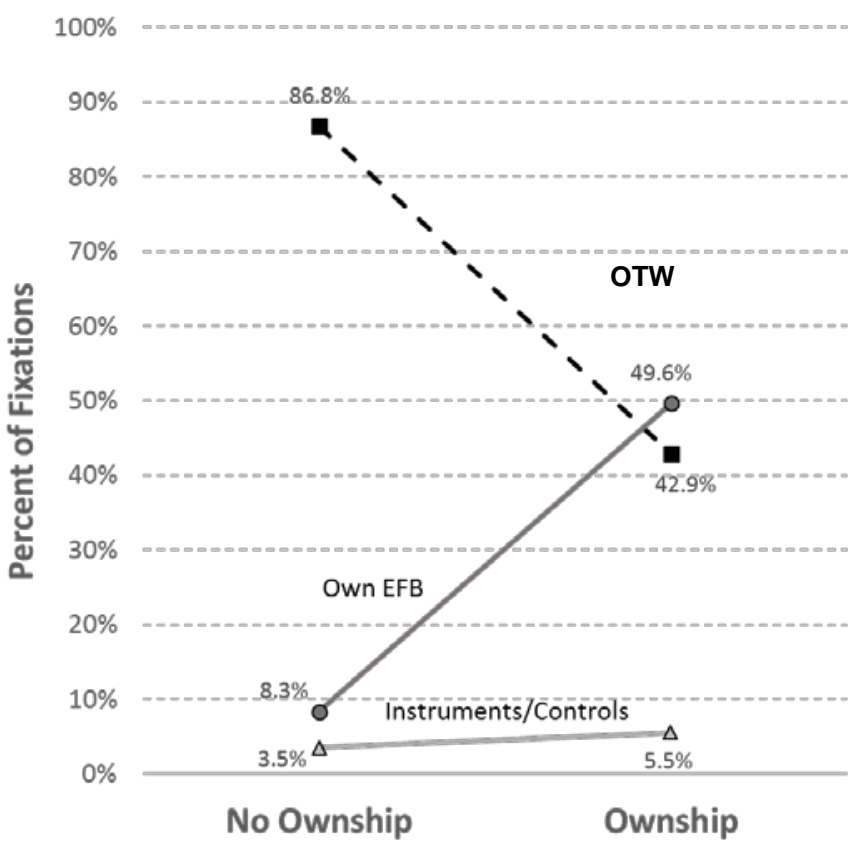

Figure 2. Percent of fixations for each area of interest for Captains.

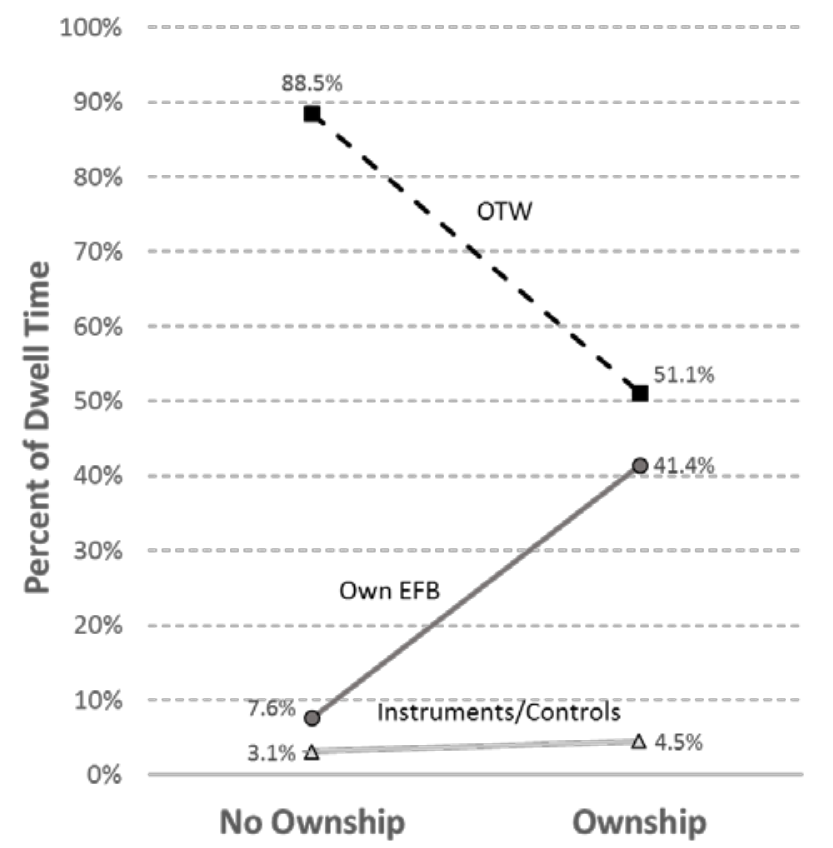

Figure 3. Percent dwell time for each area of interest for Captains.

In examining the data for First Officers, there was no significant difference in the percentage of fixations or dwell time as a function of ownship presentation. Overall, $33 \%$ of First Officers' fixations were on the electronic chart, $48 \%$ outthe-window, and $8 \%$ were on their instruments. They spent $32 \%$ of their dwell time on the EFB, $48 \%$ out-the-window, and $8 \%$ on their instruments. In considering the data in the context of the "cost" for information access, we find that there was no significant difference. First Officers, who were responsible for visually monitoring the progress of the aircraft, 
were continuously referencing the aircraft's position on the airport surface, regardless of ownship presentation.

There was no significant difference in either the number of fixations or dwell time for Captains or First Officers by RVR.

\section{GPS Error}

We conducted an analysis of the scenario where ownship position was "frozen" on the display. From the set of nine flightcrews, two flightcrews were excluded from this analysis: one due to a GPS/Bluetooth failure, and another because the GPS error occurred when the flightcrew was switching charts, and this action caused a different location to be shown on the chart. All seven flightcrews included in the analysis noticed the GPS error in approximately 1.5 minutes (range $=30$ seconds-3 minutes). No incursions were committed.

Our intent in simulating the GPS error was to create one condition to examine how pilots would respond if ownship position was incorrect, particularly after consistently seeing “perfect” positioning. Here, our simulator study was effective at simulating real-world conditions because several flightcrews identified ownship position errors in the "normal" scenarios due to a faulty Bluetooth signal. These errors were not planned as part of the experiment design.

\section{Subjective Data}

We analyzed the data from the post-scenario questionnaire using a paired $t$-test to examine ownship effects. Data for all nine flightcrews were included in this analysis. The results showed that pilots felt that they referred to the electronic chart significantly more often when it showed ownship than when it did not $(t(17)=3.60, p<0.05)$. Additionally, pilots felt the electronic chart significantly helped them in following their taxi route more when it showed ownship position than when it did not $(t(17)=4.3, p<0.05)$, and that using the chart with ownship position significantly increased the time available for other crew duties than when ownship position was not shown $(t(17)=3.5, p<0.05)$.

\section{CONCLUSIONS}

This study provides a glimpse into pilot behavior when using ownship position on electronic taxi charts in low visibility conditions. While there were three taxi errors committed across all the scenarios, no unsafe acts (incursions/excursions) were observed for any of the flightcrews, regardless of whether ownship was presented or not. We found no difference in taxi time or taxi speed due to the presentation of ownship or the visibility level. Eye tracking data showed that the presentation of ownship position influenced only the Captains' looking behavior, such that Captains looked at the electronic chart more when ownship was present than when it was absent. In the study, the Captain was responsible for taxiing/maneuvering the aircraft, so we anticipated that the Captain would be looking out the window (eyes-out) most of the time. The fact that the Captain looked more at the EFB when ownship was available suggest that showing ownship on the electronic chart was compelling. In this case, we believe that compellingness was due to the perceived utility of ownship position, so compellingness in this sense should not be interpreted as negative; rather, the presentation of ownship reduced the information access cost for determining position. This interpretation is consistent with the finding that there were no negative consequences to any other performance measure associated with ownship depiction.

This study was only a first step to defining factors contributing to display compellingness. The data in this study are limited; we only collected data from 9 flightcrews, so additional data are needed to develop a broader picture. Specifically, a better understanding is needed as to whether there are implications of the increased fixations and dwell time on the electronic chart when ownship is presented. Thus, further research is recommended to understand the impact of compellingness (a display property) in terms of human performance (attention allocation) in light of the various tasks being performed. Additionally, a metric to quantify the nature of compellingness, the contribution of the various factors that create the sense of compellingness, and the positive and negative impacts would be of value when designing and evaluating new avionics.

\section{ACKNOWLEDGMENTS}

The research was conducted under the Flight Deck Program Directive/Level of Effort Agreement between the FAA Human Factors Division (ANG-C1) NextGen Program and the Aerospace Human Factors Research Division (AAM500) of the FAA Civil Aerospace Medical Institute (CAMI). The authors would like to thank our program manager, Katrina Avers, as well as Cathy Swider (FAA); Janine King, Hunter Klevgard, Daniel Jack, Esther Devanney, and Shijing Liu of Cherokee CRC, LLC; and Stephanie Chase of the US DOT Volpe Center for their contributions. Special thanks goes to Will Ware at Southwest Airlines and Jeff Williams, Samantha Schwartz, Katie Reid, and Jason Clark at Jeppesen for their assistance in planning, developing, and executing this project. Finally, we would like to thank all the pilots who participated.

The views expressed herein are those of the authors and do not necessarily reflect the views of the Federal Aviation Administration or the United States Department of Transportation.

\section{REFERENCES}

Federal Aviation Administration. (2017). Advisory Circular (AC) 12076D, Guidelines for the Certification, Airworthiness, and Operational Use of Electronic Flight Bags. FAA: Washington, D.C.

Joslin, R. E. (2013). Human Factors Hazards of IPADS in General Aviation Cockpits. In Proceedings of the Human Factors and Ergonomics Society Annual Meeting (Vol. 57, No. 1, pp. 56-60). SAGE Publications. Wickens, C. D. and Alexander, A. (2009). Attentional tunneling and task management in synthetic vision displays. International Journal of Aviation Psychology, 19(2), 182-199.

Wickens, C. D., Goh, J., Helleburg, J., Horrey, W. J., and Talleur, D. A. (2003). Attentional models of multi-task pilot performance using advanced display technology. Human Factors, 45, 360-380.

Yeh, M. and Wickens, C. D. (2001). Display Signaling in Augmented Reality: Effects of Cue Reliability and Image Realism on Attention Allocation and Trust Calibration. Human Factors, 43(3), 355-365. 